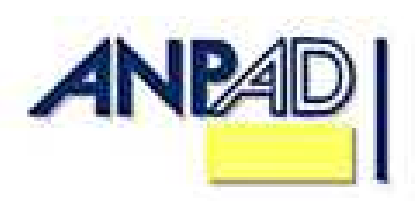

Available online at http://www.anpad.org.br/bar

BAR, Rio de Janeiro, v. 9, n. 2, art. 3, pp. 168-188, Apr./June 2012

\title{
Brand Personality Dimensions in the Brazilian Context
}

Karlan Muller Muniz *

E-mail address: karlanmuniz@gmail.com Pontifícia Universidade Católica do Paraná - PPAD/PUCPR Curitiba, PR, Brazil.

Renato Zancan Marchetti

E-mail address: renato.zancan@pucpr.br Pontifícia Universidade Católica do Paraná - PPAD/PUCPR

Curitiba, PR, Brazil.

* Corresponding author: Karlan Muller Muniz

CCSA/PUCPR, Rua Imaculada Conceição, 1155, Campus Curitiba, $1^{\circ}$ Andar, Sala 103B, Bairro Prado Velho, Curitiba, PR, 80215-901, Brazil.

Copyright (C) 2012 Brazilian Administration Review. All rights reserved, including rights for translation. Parts of this work may be quoted without prior knowledge on the condition that the source is identified. 


\begin{abstract}
Brands may be perceived as possessing a set of distinct traits or characteristics, i.e., a personality, similar to a person. Thus, the personality of a brand is relevant as a source of differentiation in an increasingly competitive market environment. In this study, the authors explore the dimensions of brand personality proposed by J. Aaker (1997), seeking to discover the particular evaluation dimensions of the Brazilian context. The study was conducted in exploratory stages, beginning with a preparatory stage that was carried out by professionals and academics from the fields of communication and marketing. This was followed by stages of conclusive research using an online survey with a sample of 1,302 Brazilian consumers. Two sub-samples were extracted: one calibration sample for exploratory factor analysis and a validation sample to perform confirmatory factor analysis in order to verify the convergent and discriminant validities of the final scale. Five dimensions of brand personality in Brazil were detected: credibility, joy, audacity, sophistication and sensitivity. These dimensions showed some differences in comparison with similar studies that had been carried out in other countries. The study led to a scale of 28 items for measuring brand personality and made it possible to compare competing brands in terms of brand personality.
\end{abstract}

Key words: marketing; brands; brand personality. 


\section{Introduction}

Over the past fifteen years, considerable research has been conducted with the purpose of defining, measuring and understanding the antecedents and consequences of building strong brands (D. Aaker \& Biel, 1993). As competition has intensified and a market has similar alternatives of products and services within the different sectors and branches, branding has increasingly come to be viewed as a differentiating element and is evaluated by the consumer beyond its rational and functional aspects.

Authors who approach brand management as a natural expansion of product or product portfolio management see the need to understand the facets that brands represent or wish to impose on consumers (D. Aaker, 1996; Kapferer, 2003; Keller, Aperia, \& Georgson, 2008). Among the facets that make up brand identity (such as physical features, relationship with the consumer and reflected culture), one of the intangible attributes with a potential for differentiation in a competitive environment is brand personality.

This study seeks to further the studies of brand personality, identifying its main dimensions in Brazil, validating a measurement scale and comparing the results with the scale proposed by J. Aaker (1997) in the United States and other contexts. This article is divided into three parts. The first reviews the literature on the subject. The second introduces the methodology employed to gather data. The third part reports the results and also provides the conclusions, implications and limitations of the study.

\section{The Brand as a Multidimensional Construct}

Keller (2003) states that branding involves the process of providing products and services with advantages that, over time, will lead to the construction of a strong brand. According to this author, a brand introduces a series of dimensions through which the consumer considers it, forming multiple facets of brand knowledge.

Examples of the importance of a brand in the differentiation of similar products in the Brazilian context are the work of Cunha, Luce and Klering (1997), focusing on yogurt, and that of Urdan and Urdan (2001), focusing on beer consumption. Both studies test and confirm this assumption, showing that the brand is just one element (Urdan \& Urdan 2001) that helps determine how consumers make their choices.

One study that sought to group the definitions and visions of academics and professionals conceived brand as a multidimensional construct through which managers add values to products and services, thereby facilitating the recognition and appreciation of these values by consumers (Chernatony \& Riley, 1998). This definition enriches the concept proposed by the American Marketing Association in 1960, according to which the brand may be defined as a name, term, sign, symbol and design (or a combination of these) that identifies the manufacturer or seller of products or services and differentiates them from the competition (Chernatony \& Riley, 1998; D. Aaker, 1998).

According to Keller $(1993,2003)$, much attention has been paid to brands and their dimensions, and the understanding of the different brand associations provides a guideline for marketing strategies, aiding decision making. Keller, Apéria and Georgson (2008) claim that the strength of a brand lies in the clients' minds (brand awareness and image) and that professionals and researchers should construct a detailed map of the knowledge about the brand in the minds of consumers. Keller (1993) and D. Aaker (1996) view the composition of brand knowledge as a set of both tangible/intangible and objective/subjective associations that compose the brand image. Corroborating these notions and broadening the meanings and representations that are added over time, the brand is defined as a 
reference point for all the positive and negative impressions formed by the consumer over time, taking into account the product, distribution network, its staff, and its advertising and publicity (Kapferer, 2003). One of the impressions formed by consumers and which can result in differentiation and identification with the consumer is brand personality.

\section{Brand Personality}

Over the last decade, brand personality has drawn the attention of researchers. Many scholars have asked whether products and brands could have their own personalities and whether these brands, because of this dimension, could evoke feelings, emotions and behaviors, in the same way that human beings are branded as outgoing, friendly, aware and intelligent (Caprara, Barbaranelli, \& Guido, 1998). Researchers such as Plummer (1985), Berry (1988) and Durgee (1988) argue that brands, like humans, can also be assigned personality profiles that are defined through a series of attributes.

The personality of a company, product or brand has been recognized in the field of marketing since the 1950's (Gardner \& Levy, 1955; Levy, 1959; Martineau, 1958). In the Brazilian context, De Toni and Schuler (2003) approached the concept of product image, with emphasis on product personification: products acquire a personality similar to that of a person. Brand personality was widely recognized in the 1980's, becoming popular among marketing and publicity professionals and researchers (Caprara et al., 1998). Brands can be characterized as modern, classic, cheerful, or exotic, to name a few, just like people. Furthermore, according to how the personality of a brand is perceived, consumers end up deciding whether that brand is suitable for them or represents them better.

Plummer (1985), Durgee (1988) and Berry (1988) confirmed the importance of brand personality for differentiation and a resource for advertising and publicizing the brand. D. Aaker (1996) claims that brand personality reflects a richer and more interesting reality than any reality solely based on product attributes. Biel (1993) describes brand personality as a booster and a relevant component of a brand's image: its perceived value; since brand personality is part of a richer metaphoric and symbolic vocabulary than that represented by the physical and functional characteristics of the brand/product. Chernatony and Riley (1998) refer to brand personality as a way of sustaining its unique nature, underlining psychological values, bearing in mind the capacity of competitors to emulate and overcome functional advantages.

Batra, Lehmann and Singh (1993) define brand personality as how a consumer understands the brand in dimensions that typically capture a person's personality. According to these authors, there are many concepts of brand personality, as is the case with the construct of a human personality. For example, a brand personality is a constructed characteristic that becomes a differential (Biel, 1993; Plummer, 1985) and can also be considered a metaphor that describes characteristics that are considered stable (Caprara et al., 1998).

Brand personality is conceived and operationalized in this study as "the set of human characteristics associated with a brand" (J. Aaker, 1997, p. 347). In this light, the brand may be described by the personality traits that resist the pressures of time and are found in its behavior and discourse, as in advertising campaigns, the use of brand characters and so on (Keller et al., 2008).

\section{Antecedents and Effects of Brand Personality}

From the moment when it is first publicized, through products and advertisements, the brand takes on a character and, by reading between the lines of its discourse, it is possible to identify what kind of person this brand would be should there be a desire to draw a comparison between the brand 
and a person (Kapferer, 2003). J. Aaker (1997) claims that the symbolic use of brands is possible because consumers generally imbue a brand with human personality traits.

Exploring the antecedents of brand personality, Biel (1993) claims that brand personality is the result of interaction between the brand and consumers. Other authors point out that consumers do not receive brands passively (Fournier, 1998; Zaltman, 2003). Fournier (1998) states that marketing professionals and consumers together create brand meanings and that brand personality can be seen as the inference of a group of traits constructed through repeated observation of the brand's behavior by the consumer along with the perception of the brand as a partner in a daily relationship.

D. Aaker (1998) describes product-related characteristics (category, packaging, price and functional attributes) and lists a series of characteristics that are not associated with the product (image of a typical user, brand sponsorships, age, advertising style, country of origin, company image, company owner's image and celebrity endorsements of the brand) as sources of product personality development. Grohmann (2009) demonstrates, for instance, that a brand spokesperson, a poster boy or girl, influences how brand personality is perceived.

Concerning the effects of brand personality, previous studies have shown that, in addition to the potential for differentiation of a brand personality in a given competitive environment, this facet plays a fundamental role in the relationship with the consumer. Research in the field of consumer behavior has looked at how brand personality allows the consumer to express the image that he or she has of himself or herself (Ferrandi, Merunka, Valette-Florence, \& De Barnier, 2002). Shank and Langmeyer (1994) showed that perceived brand personality can go farther still and be independent of consumer personality, because individuals with very different personalities see the product or brand personality in a similar way. A recent study, which focuses on the gender aspects (masculine/feminine) of brand personality, shows that when there is congruence between perceived brand personality and the selfconcept of the consumer, responses are more positive when it comes to a favorable attitude to the brand, preference for the brand over competing brands, a high level of affection and trust, and a high degree of loyalty to the brand in terms of attitude and behavior (Grohmann, 2009).

From a different point of view, Fournier (1998) framed brand personality in terms of its role in the relationship with the consumer. According to this author, brand personality, made visible through its behavior (marketing actions and decisions), suggests a type of commitment to the consumer, which can range from that of an arranged marriage (a relationship with the brand because of a third party, involuntarily) to passion (affinity and adoration) (Keller et al., 2008).

More recent studies propose a scale for measuring brand experience and testing brand personality constructs and brand experiences that, through the application of a structural equation, indicated a direct effect between brand experience and perception and the strength of the brand personality, which in turn had a direct effect on consumer satisfaction and loyalty (Brakus, Schmitt, \& Zarantonallo, 2009). According to the authors, the social and self-expressive characteristic of the brand personality may account for its participation as an antecedent of satisfaction and loyalty. To operationalize the concept and test its antecedents and effects, it is necessary to explore a measurement scale that is reliable and valid for brand personality.

\section{Measuring Brand Personality}

The literature shows that there are gaps to be explored on the subject of brand personality. Many authors have begun to debate and write about brand personality (Batra, Lehman, \& Singh, 1993; Biel, 1993; J. Aaker \& Fournier, 1995), seeking to conceptualize it, discussing ways of measuring it and estimating its implications for human behavior. In principle, the methods for measuring brand personality involve the use of projective techniques (Keller et al., 2008) and quantitative check-lists (J. Aaker, 1997). Another procedure for measuring personality is the use of scales developed to gauge 
human personality (Goldberg, 1990), using the same traits that compose this tool when used in psychology. Caprara, Barbaranelli and Guido (1998) suggest that personality as a metaphor of the brand can follow a similar procedure to that used with human personality to distinguish dimensions that are powerful enough to describe and amass the other traits. Nevertheless, studies have shown that a simple transposition from the human personality scale to a brand personality scale is not adequate. Caprara, Barbaranelli and Guido (2001) stated that the traditional repertoire of human personality can be used to construct brand personality, but only up to a certain point. J. Aaker (1997) observed that although some dimensions may be reflected in brands, others should not be.

J. Aaker (1997)'s research established a theoretical framework for the construct of brand personality, operationalizing the concept and determining a number of dimensions that make up brand personality, describing the nature of these dimensions as a set of personality traits. To construct a scale to measure brand personality, J. Aaker (1997) made use of the psycholexical approach, commented on by some of the main scholars of human personality (Allport, 1973; Nuttin, 1969). This approach states that the numerous attributes used to describe human personality can be described by a limited number of classes or latent dimensions, using factor analysis measurements that reveal, in the case of human personality, a structure that is generally composed of five major factors (a model known as the Big Five human personality dimensions). J. Aaker (1997), as a result of her study, identified five large brand personality dimensions: sincerity, excitement, competence, sophistication and ruggedness. Thus, a reliable, valid and generalizable measuring scale was created in the American context, facilitating further study of other matters concerning brand personality. Figure 1 describes the five dimensions, fifteen facets and forty-two traits that make up the brand personality scale in the American context.

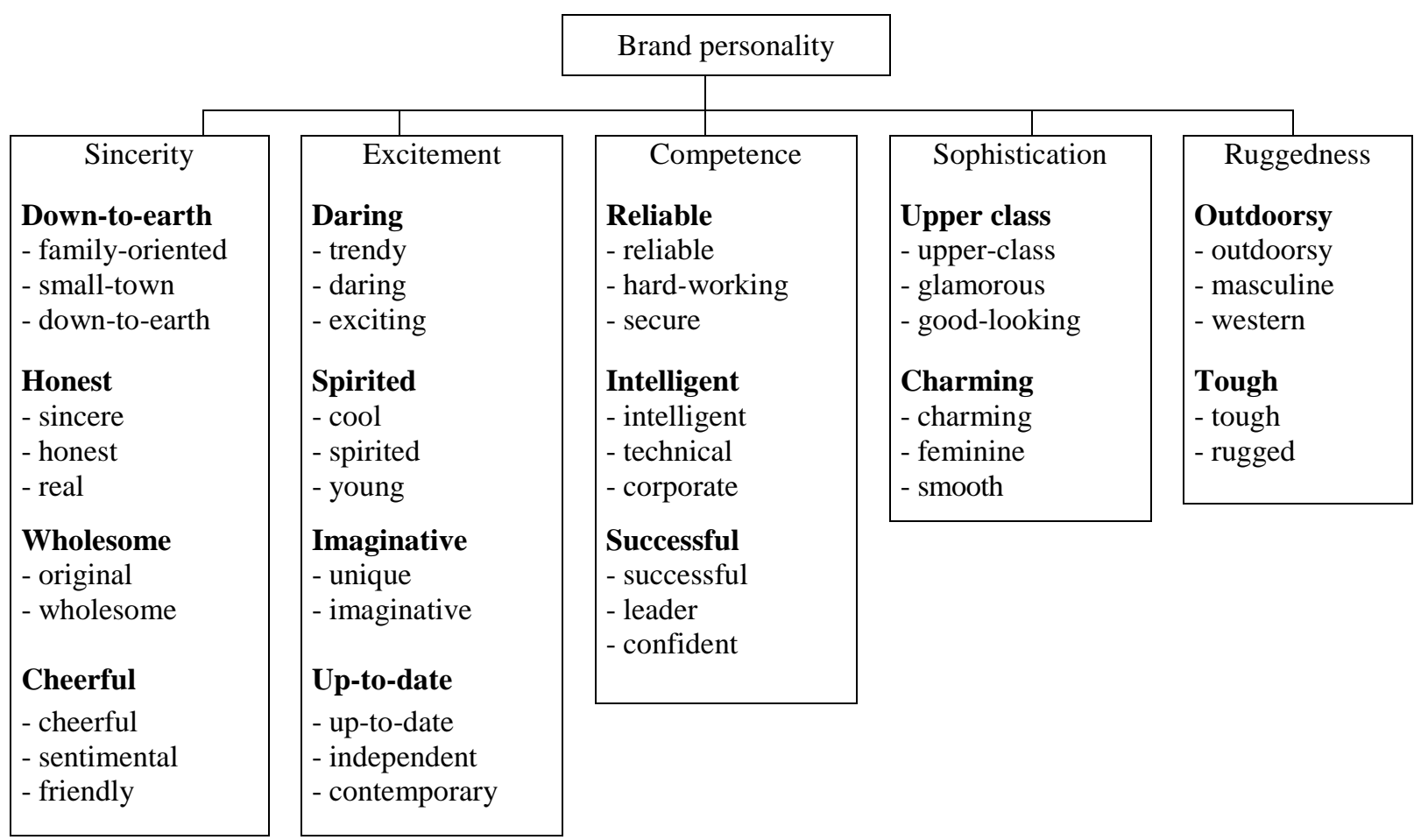

Figure 1. Brand Personality Scale.

Source: Aaker, J. (1997). Dimensions of brand personality (p. 352). Journal of Marketing Research, 34(3), 347-356. doi: $10.2307 / 3151897$

An article by Azoulay and Kapferer (2003) criticized the definition of J. Aaker (1997), mentioning that her very global scale and operational definition are erroneous, going beyond personality in itself and mixing other dimensions of brand identity that should be kept separate in the theoretical context and practical use; such as skills, gender and adjectives that involve social class, for instance. A Brazilian study, conducted by Pontes and Parente (2008), draws comparisons and applies the brand personality scale proposed by J. Aaker (1997) and the scale recommended by Azoulay and 
Kapferer (2003); the latter is a proposal that maintains the concept of the trait factor derived from psychology and the measurement of human personality. The study of Pontes and Parente (2008) reaffirms the utility of the scale proposed by J. Aaker (1997) as an analysis tool, demonstrating that both approaches achieve similar results.

J. Aaker (1997) also states the need to test and/or develop scales for understanding the symbolic use of brands in other contexts in different cultures. Although human personality dimensions show ruggedness when applied to other cultures, the same cannot be said for brand personality because of the differences between the antecedents of the two constructs (J. Aaker, 1997).

As would be desirable for every newly conceived scale or theoretical framework, the J. Aaker's (1997) scale was replicated or constructed in a number of different studies in other contexts (J. Aaker, Benet-Martinez, \& Garolera, 2001; Supphellen \& Gronhaug, 2003), showing some similarities and some variations in the dimensions of brand personality and their findings.

J. Aaker, Benet-Martinez and Garolera (2001) state the need for an Emic/Etic approach for measuring brand personality in another context, since the emic approach seeks to explore the construct from within the cultural system in question, while the imposed-etic approach involves imported structures and scales.

In both contexts where the scale construction research was replicated (Japan and Spain), the authors began by identifying the origin of the brand personality dimensions, using a process similar to that used by J. Aaker (1997) in her original study. In the Japanese context there were five dimensions and thirty-six facets. There was no Ruggedness dimension as in the American study, and another stronger third dimension, Peacefulness, was identified. To the authors, this dimension may be explained by the cultural differences between the contexts, resulting in differences of perception and attitude regarding brands.

Using the same process in Spain, J. Aaker et al. (2001) identified five dimensions and 33 facets in brand personality in the context of that country. In addition to the Sincerity, Excitement and Sophistication dimensions (that also existed in the USA and Japan), Peacefulness (found in Japan but not in the USA) and Passion (not found in the other two countries) were identified. The passion dimension is commonplace in the Southern Europe, in countries with Catholic cultures, according to the literature accessed by the authors.

Therefore, for the construction of a brand personality scale in the Brazilian context, a procedure was used that was similar to that used in the studies by J. Aaker (1997) and J. Aaker et al. (2001). It might be expected that there would be similarities with the dimensions found in other countries (seeing that brands carry common meanings and are globalized); and there could also be dimensions that carry values that are unique to the local culture.

\section{Method}

The aim of this study is to identify brand personality dimensions in the Brazilian context, expanding the understanding of this field of research. The study was conducted following the eight stages outlined below in accordance with some of the stages described by Churchill (1979) when constructing the scales.

In the first stage, there was a reverse translation of the items/characteristics used on the American scale (J. Aaker, 1997) and the total items used in the study from which the Japanese and Spanish scale originated (J. Aaker et al., 2001). Using this method, the scale was translated from English to Portuguese by two professors who are native Portuguese speakers, are fluent in English, and live in Brazil. The two translations were done independently and the expressions that were not agreed upon at first were discussed in the second step of this process. The final traits in the Portuguese 
language were then translated back into English by professors who are native speakers of English but have lived in Brazil. This process sought to ensure a precise translation of the traits (adjectives and characteristics) and their meanings.

The second stage involved in-depth interviews with three researchers and three professionals (publicity agents and consultants) in charge of the publicity and management of brands. Interviews were selected from the upper echelons of their organizations with individuals who were in charge of analyzing and constructing brands in the Brazilian context. After sounding out over a dozen professionals and researchers, the final sample was made up of those who were available to participate in the study. This phase was concluded when it was felt that the responses to the survey were rich and of a high standard, even though the sample was small. The aim of this stage was not to generate items but rather to evaluate the indicators and items obtained in the previous stage and validate the nature of the brand personality construct in the Brazilian context. This sample proved to be sufficient due to the quality of the participants and considering the theoretical saturation of the information obtained (Gummesson, 2005; Merkens, 2004), when little or no additional relevant information can be obtained by increasing the sample.

In the third stage, the unification of traits identified following the reverse translation, together with the traits added by the interviewees and some characteristics researched by the authors in dictionaries of human personality traits, resulted in a list of 174 traits.

With a view to filtering the total set of traits to a manageable volume with the final consumer, in the fourth stage a questionnaire was given to the professionals and professors with experience in the field of marketing to evaluate how much of each trait can be found or seen in the brands. A 7-point scale was used (ranging from $1=$ this characteristic in no way describes the brand to $7=$ this characteristic fully describes the brand). The respondents were told that the questionnaire did not deal with one specific brand or category but sought to understand how much each characteristic described different brands in different categories of product. This questionnaire was sent to thirty respondents (located in the states of São Paulo, Paraná, Santa Catarina and Rio Grande do Sul). Twenty-four valid questionnaires were returned. Having analyzed the distribution of frequency and the central trend (median) results, a decision was made to make a cut after the second quartile of traits that best described the brands. The final list was therefore reduced to 87 traits. All the traits selected had a median of over 5.00 (point of the scale that states this characteristic describes the brand).

Stage five involved collecting data from consumers. To obtain a sample at a nationwide level, and bearing in mind the time and financial limits of the project, we decided to prepare an online questionnaire with its own domain name (http://www.pesquisamarcas.com) with professional structuring of the site in terms of design and database. The sample is non-probabilistic and has the characteristics of those Brazilians who access the internet. The site was made known to people nationwide through e-mail marketing and banners on supporting websites.

For this stage, twenty-four brands of twelve categories of products and services were selected. The selection aimed to include brands from different categories such as hygiene and beauty products, cleaning products, food, drinks, sweets, footwear, durable products such as cars and cell phones and a category of services (banks). Broadening the spectrum of categories of products and services has the advantage of increasing the chances of generalization and robustness of the measurement scale, with the scale providing a wide range of traits of a number of different brands. This procedure was similar to that used in other countries (J. Aaker, 1997; J. Aaker et al., 2001). However, to make sure that the questionnaires were not tiring and inconvenient to complete, when accessing the website online, the respondent was required to evaluate only two brands, chosen at random by the database. The authors were careful to make sure that two competing brands would not be evaluated by the same respondent.

Respondents were asked to fill out a questionnaire evaluating how well certain characteristics described the chosen brands on a scale of one to ten $(1=$ this characteristic in no way describes the brand; $10=$ this characteristic fully describes the brand). To encourage participation, seeing that it was an extensive questionnaire, the respondents were informed that they would be included in a prize 
drawing (approximately $\$ 40$ reais, or US\$20 at the time of the study) for shopping tokens. The use of incentives in online surveys has its advantages, such as a higher response rate and less likelihood of a respondent dropping out of the survey (Cobanoglu \& Cobanoglu, 2003; Deutskens, Ruyter, Wetzels, \& Oosterveld, 2004; Goritz, 2006). However, offering prizes can also threaten the validity of the study because it may attract people who are only interested in the prize (Goritz, 2006). A measure adopted to maintain a balanced quality of responses was to present the questions (traits) and brands used in the study in a random fashion, as recommended by Frippiat and Marquis (2010), in addition to analyzing and excluding respondents with high rates of unanswered questions or high rates of very similar responses, with little variation on the 1 to 10 scale, when evaluating the traits. Visual elements of the brands were also used in the questionnaire to hold the attention and interest of the respondents, as suggested by Deutskens, Ruyter, Wetzels and Oosterveld (2004). The data collection began on February 17, 2005, and continued until March 13, 2005, a period of time set by the researchers during which the link was available nationwide. The study was concluded with a total of 1,302 respondents (valid questionnaires). As each respondent evaluated two brands, a total number of 2,604 cases were computed in the survey (1,302 respondents evaluating 2 brands each). In stage six, five traits were excluded because they exhibited a high rate of the response of I don't know (the eleventh point on the scale). This left 82 traits that would be used in the data analyses aiming to answer the research question.

In the seventh stage, exploratory factor analysis was used with to the intent of condensing or summarizing the information contained in the different original variables into a smaller set of new dimensions (factors) with a minimum loss of information in an effort to define the main dimensions inherent to the original variables (Hair, Anderson, Tatham, \& Black, 2005). With a desire to perfect the scale development, the split-half technique was used (Churchill, 1979) on the total sample of respondents $(1,302)$. As each respondent analyzed two brands, the bases of the first and second brands were separated and from them the two calibrations samples were extracted at random, in order to apply the exploratory factor analysis to half of the cases $(n=651)$, with two different sets of data for each brand that was evaluated. Two more random samples of the same size were then extracted (651 for each brand), known as the validation sample, where confirmatory factor analysis was applied. In the exploratory factor analysis, the main component analysis was used, which is employed when the aim is to summarize most of the original information (variance) to a minimum number of factors for purposes of forecasting (Hair et al., 2005). A VARIMAX rotation was also used, in order to achieve a simpler and more significant factorial pattern (Malhotra, 2001). In this stage, the resulting dimensions were analyzed and indicators, such as Cronbach's Alpha, were used as a reference measurement to estimate reliability between different items: a measurement of the internal consistency of the dimension (Hair et al., 2005). The two structures of dimensions resulting from the two exploratory factor analyses were supported by the following criteria: more significant factors that were easier to interpret, evaluation of the eigenvalues, significant variance explained by the dimensions and the internal consistency of the dimensions (Cronbach's Alpha). With the resulting dimensions of the calibration sample in hand, a confirmatory factor analysis was used to verify the behavior and the adjustment indexes of the resulting models in order to select the most suitable structure of dimensions, refine the final traits and prove the validity of the final proposed scale. The validation sample was separated into two groups (evaluation of the first and second brand) to ensure levels of reliability and validity of the scale in the confirmatory analysis. The adjustment indicators of this type of model were evaluated in order to choose and validate the most adequate model.

In the eighth stage, with the five dimensions of brand personality consolidated, it was possible to evaluate each of the 24 brands used in the study according to their scores within each of the brand personality dimensions. 


\section{Research Results}

\section{Preparatory phase}

The results of the in-depth interviews show that brand personality is viewed as an intangible but powerful facet because it has a distinctive essence, a set of values that are consolidated with the brand over time and which can help differentiate it when there is parity in relation to tangible or functional aspects. These definitions and opinions corroborate the definition and importance given to brand personality in the literature (J. Aaker, 1997; Keller et al., 2008). Having a strong personality, in the opinion of the interviewees, is to reach a higher stage in the brand evolution process. In this article, the brand is seen as something bigger than the product or service and as it grows stronger in these dimensions it is capable of expanding to other businesses (brand extension).

The in-depth interviews allowed the interviewees to evaluate the resulting traits from reverse translation. This procedure helps in the validation because, although subjective, it is a systematic evaluation of how well the content of a scale represents that which must be measured. This evaluation by the interviewees resulted in the recommendation and addition of new characteristics such as formal and sensitive to the set of traits.

\section{Development of the scale}

After the traits were filtered in a preparatory stage with 24 marketing professionals and professors, and after the removal of traits with high I don't know rates following research with the end consumer, a factor analysis with the 82 results was conducted in an effort to reduce them to dimensions representing the phenomenon. The final sample of 1,302 respondents was composed of $40.9 \%$ young people under the age of twenty-five, $53.3 \%$ men and $92.2 \%$ of the respondents were of the top two social classes. This profile is very similar to that of Brazilians were had access to the internet at that time (http://www.e-commerce.org.br).

The split-half technique was used and half of the sample, selected at random, was used for two exploratory factor analyses, separating the analysis of Brand 1 and the analysis of Brand 2 that were done by each of the interviewees.

In both cases, indexes that test the correlation between the variables and the adequacy of the factor analysis to the data structure had adequate levels. The resulting KMOs of the two exploratory factor analyses are considered admirable according to Hair, Anderson, Tatham and Black (2005), with indexes of 0.961 and 0.960 , respectively. The Bartlett test also had factor analysis adequacy through the chi-square test and the degrees of freedom $\left(\chi^{2}=29384.495 ; \mathrm{df}=3321 ; \mathrm{p}<0.001\right.$ in the first analysis and $\chi^{2}=29678.057 ; \mathrm{df}=3321 ; \mathrm{p}<0.001$ in the second).

Using the main component analysis and using a VARIMAX rotation to achieve a simpler and more significant factorial pattern (Malhotra, 2001), in the first analysis five dimensions were found that represent $52.52 \%$ of the explained variance. In the second sample four dimensions were identified, representing $50.74 \%$ of the explained variance. It is worth mentioning that two of the dimensions in the first five-factor model appear to have become fused in the second, four-factor model. The adequacy of the five factors in the first and the four factors in the second exploratory factor analysis was supported by the following criteria: the first factors proved to be more significant and interpretable; at least five traits loaded in the first five factors (with loading of over 0.440) and the variance explained by the first dimensions was much higher than the other dimensions.

The traits belonging to each dimension, found in both analyses, were then filtered, and those items with very low loading were eliminated (in most cases under 0.410), along with those that caused a certain redundancy with other factors in the dimensions, those that were positioned in more than one dimensions and those that had little consistency in the Cronbach's Alpha. 
In the first exploratory factor analysis, the Alphas varied from 0.84 to 0.93 in the five dimensions, considering a total of 46 traits, while in the second exploratory factor analysis the Alphas varied from 0.88 to 0.93 , considering a total of 48 traits. According to Hair et al. (2005), the lowest limit for the Alpha to be accepted is 0.70 , although this can be lowered to 0.60 in exploratory studies.

\section{Verifying the validity of the scale}

In the exploratory factor analysis conducted on the calibration sample, two dimensional structures with five and four dimensions, respectively, were identified. In order to test the two dimensional structures suggested for the verification of the model with better adjustment indexes and to select the final traits to compose the scale of brand personality in Brazil, we employed a confirmatory factor analysis procedure. As mentioned above, a validation sample was used, divided into two sets of data: a confirmatory analysis was conducted using the evaluations of Brand 1 and another confirmatory factor analysis was conducted using the evaluations of Brand 2. In the first set, which originally had 651 cases, 578 remained in the analysis, with the removal of the missing values and cases where the respondent answered "I don't know" to a certain trait. Of the 651 cases in the second set of data, 602 remained.

A comparison was made, using confirmatory factor analysis, of the adjustment indexes of the two rival models originating from the exploratory procedures. For this purpose, one of the sets of data from the validations sample was used (in this case, the evaluation of Brand 1). In this analysis, the five-dimension model was perceived to have much higher adjustment indexes $(\mathrm{X} 2=1408.724$; df: 340; p< 0.001; X2/df: 4,134; GFI: 0,843; NFI: 0,876; RFI: 0,863; IFI:0,903; TLI: 0,892; CFI: 0,903; RMSEA: 0,074) than those found in the four-dimension model (X2 = 1986.321; df: $344 ; \mathrm{p}<0.001$; X2/df: 5.513; GFI: 0.776; NFI: 0.834; RFI: 0.817; IFI: 0,860; TLI: 0.845; CFI: 0.852; RMSEA: 0.088 ). This analysis confirmed the better suitability of the five-dimension structures over the rival four-dimension structure.

The samples served to develop a confirmatory factor analysis (Hair et al., 2005), for the purpose of verifying the convergent and discriminant validities of the final scale. The indicators that had low loadings for each latent variable were removed from this process. This resulted in 28 indicators integrated into the five dimensions resulting from the scale development stage. These are shown in Table 1. In this table the results for the two samples in question are shown, with the loadings in each dimension, the composite reliability indicators and average variance extracted (Fornell \& Larcker, 1981), as well as the adjustment indicators of the CFA model.

Table 1

\section{Confirmatory Factor Analysis (Validation Sample)}

\begin{tabular}{|c|c|c|c|c|c|c|c|}
\hline & & \\
\hline & & \multicolumn{3}{|c|}{ First brand sample $(n=578)$} & \multicolumn{3}{|c|}{ Second brand sample $(\mathrm{n}=602)$} \\
\hline & & Loading & $\begin{array}{l}\text { Composite } \\
\text { Reliability }\end{array}$ & $\begin{array}{c}\text { Average } \\
\text { Variance } \\
\text { Extracted }\end{array}$ & Loading & $\begin{array}{l}\text { Composite } \\
\text { Reliability }\end{array}$ & $\begin{array}{c}\text { Average } \\
\text { Variance } \\
\text { Extracted }\end{array}$ \\
\hline \multirow{8}{*}{ Credibility } & Responsible & $0,819 *$ & \multirow{8}{*}{0.921} & \multirow{8}{*}{$59.5 \%$} & $0.763^{*}$ & \multirow{8}{*}{0.902} & \multirow{8}{*}{$53.6 \%$} \\
\hline & Secure & $0.823^{*}$ & & & $0.794 *$ & & \\
\hline & Reliable & $0.805^{*}$ & & & $0.745^{*}$ & & \\
\hline & Confident & $0.778 *$ & & & $0.743 *$ & & \\
\hline & Correct & $0.753 *$ & & & $0.752 *$ & & \\
\hline & Respectable & $0.779 *$ & & & $0.732 *$ & & \\
\hline & Loyal & $0.740^{*}$ & & & $0.678^{*}$ & & \\
\hline & Consistent & $0.662 *$ & & & $0.641^{*}$ & & \\
\hline
\end{tabular}


Table 1 (continued)

\begin{tabular}{|c|c|c|c|c|c|c|c|}
\hline & & & & & & & \\
\hline & & \multicolumn{3}{|c|}{ First brand sample $(n=578)$} & \multicolumn{3}{|c|}{ Second brand sample $(n=602)$} \\
\hline & & Loading & $\begin{array}{l}\text { Composite } \\
\text { Reliability }\end{array}$ & $\begin{array}{l}\text { Average } \\
\text { Variance } \\
\text { Extracted }\end{array}$ & Loading & $\begin{array}{l}\text { Composite } \\
\text { Reliability }\end{array}$ & $\begin{array}{l}\text { Average } \\
\text { Variance } \\
\text { Extracted }\end{array}$ \\
\hline \multirow{7}{*}{ Joy } & Cool & $0.696^{*}$ & \multirow{7}{*}{0.925} & \multirow{7}{*}{$64.0 \%$} & $0.645^{*}$ & \multirow{7}{*}{0.913} & \multirow{7}{*}{$60.4 \%$} \\
\hline & Happy & $0.803^{*}$ & & & $0.813^{*}$ & & \\
\hline & Festive & $0.763 *$ & & & $0.706^{*}$ & & \\
\hline & Extrovert & $0.846^{*}$ & & & $0.845^{*}$ & & \\
\hline & Fun & $0.832 *$ & & & $0.825^{*}$ & & \\
\hline & Good-natured & $0.845^{*}$ & & & $0.815^{*}$ & & \\
\hline & Playful & $0.808 * *$ & & & $0.773 * *$ & & \\
\hline \multirow{4}{*}{ Audacity } & Modern & $0.744 *$ & \multirow{4}{*}{0.848} & \multirow{4}{*}{$58.4 \%$} & $0.737 *$ & \multirow{4}{*}{0.809} & \multirow{4}{*}{$51.5 \%$} \\
\hline & Daring & $0.761^{*}$ & & & $0.704 *$ & & \\
\hline & Creative & $0.810^{*}$ & & & $0.744 *$ & & \\
\hline & Up-to-date & $0.741 *$ & & & $0.686^{*}$ & & \\
\hline \multirow{5}{*}{ Sophistication } & Chic & $0.867 *$ & \multirow{5}{*}{0.903} & \multirow{5}{*}{$65.2 \%$} & $0.854^{*}$ & \multirow{5}{*}{0.905} & \multirow{5}{*}{$65.7 \%$} \\
\hline & Elegant & $0.838^{*}$ & & & $0.845^{*}$ & & \\
\hline & Upper class & $0.781 *$ & & & $0.777 *$ & & \\
\hline & Sophisticated & $0.846^{*}$ & & & $0.844^{*}$ & & \\
\hline & Glamorous & $0.695^{*}$ & & & $0.727 *$ & & \\
\hline \multirow{4}{*}{ Sensitivity } & Romantic & $0.709^{*}$ & \multirow{4}{*}{0.824} & \multirow{4}{*}{$54.0 \%$} & $0.670^{*}$ & \multirow{4}{*}{0.811} & \multirow{4}{*}{$51.8 \%$} \\
\hline & Delicate & $0.722^{*}$ & & & $0.724 *$ & & \\
\hline & Sensitive & $0.760 *$ & & & $0.715^{*}$ & & \\
\hline & Enchanting & $0.748 * *$ & & & $0.767 * *$ & & \\
\hline \multicolumn{2}{|c|}{ CFA Model Indicators } & \multicolumn{3}{|c|}{$\begin{array}{c}\mathrm{X}^{2}=1408.724 ; \mathrm{df}=340 ; \mathrm{X}^{2} / \mathrm{df}=4.134 ; \\
\mathrm{CFI}=0.903 ; \mathrm{NFI}=0.876 ; \mathrm{TLI}=0.892 ; \\
\quad \text { GFI }=0.843 ; \mathrm{RMSEA}=0.074\end{array}$} & \multicolumn{3}{|c|}{$\begin{array}{c}\mathrm{X}^{2}=1404.443 ; \mathrm{df}=340 ; \mathrm{X}^{2} / \mathrm{df}=4.131 ; \\
\mathrm{CFI}=0.897 ; \mathrm{NFI}=0.868 ; \mathrm{TLI}=0.885 ; \\
\quad \text { GFI }=0.846 ; \mathrm{RMSEA}=0.072\end{array}$} \\
\hline
\end{tabular}

Note. Key: $* \mathrm{p}<0.01$; ** significance not calculated because the co-efficient is set at 1 for model identification.

Source: Research Data.

The results show a consistent model in terms of composite reliability values (all over 0.70 ) and average variance extracted (all over 50\%), in accordance with the criteria of Fornell and Larcker (1981) and Hair et al. (2005). Likewise, the global adjustment of the CFA models also achieved acceptable indicators, in accordance with Hair et al. (2005). According to the last line of the table, the CFI, NFI and TLI indicators were very close to 0.900 . The GFI index, which was around 0.845 , has an acceptable level, since higher values are a sign of better adjustment, although there are no established references (Hair et al., 2005). The RMSEA, index of 0.07 can be considered a good adjustment (Maroco, 2010). Despite the $\mathrm{X}^{2}$ value being high, the relationship of $\mathrm{X}^{2}$, divided by the number of degrees of freedom had low values (under 5). Thus, in accordance with the criteria of Fornell and Larcker (1981) and Hair et al. (2005), the convergent validity of the scale in question was confirmed.

To confirm the discriminant validity, the correlation between the latent variables must be evaluated. These are shown in Table 2. The table shows the correlations between the proposed dimensions for the two sets of data used in the validation sample. 
Table 2

Correlation between the Dimensions of the Model

\begin{tabular}{|c|c|c|c|c|}
\hline \multicolumn{3}{|c|}{ Correlated Dimensions (analysis in pairs) } & \multirow{2}{*}{$\begin{array}{c}\begin{array}{c}\text { Correlation for } \\
\text { first brand } \\
\text { (validation } \\
\text { sample) }\end{array} \\
0.508^{*}\end{array}$} & \multirow{2}{*}{$\begin{array}{c}\begin{array}{c}\text { Correlation for } \\
\text { second brand } \\
\text { (validation } \\
\text { sample) }\end{array} \\
0.488^{*}\end{array}$} \\
\hline Credibility & $\langle-->$ & Audacity & & \\
\hline Credibility & $\langle-->$ & Sophistication & $0.569 *$ & $0.542 *$ \\
\hline Sensitivity & $\langle-->$ & Credibility & $0.557 *$ & $0.493 *$ \\
\hline Credibility & $\langle-->$ & Joy & $0.199 *$ & $0.156^{*}$ \\
\hline Audacity & $<-->$ & Sophistication & $0.594 *$ & $0.673^{*}$ \\
\hline Sensitivity & $\langle-->$ & Audacity & $0.543 *$ & $0.560^{*}$ \\
\hline Joy & $<-->$ & Audacity & $0.689 *$ & $0.680^{*}$ \\
\hline Sensitivity & $<-->$ & Sophistication & $0.652 *$ & $0.655^{*}$ \\
\hline Joy & $<-->$ & Sophistication & $0.185^{*}$ & $0.257^{*}$ \\
\hline Sensitivity & $\langle--\rangle$ & Joy & $0.480 *$ & $0.549^{*}$ \\
\hline
\end{tabular}

Note. $* \mathrm{p}<0.01$

Source: Research data.

The first aspect of this table is that none of the correlations was very high. To evaluate the discriminant validity among these dimensions, the criterion of Fornell and Larker (1981) was used. These authors suggest that the average variance extracted in each latent variable (dimension) cannot be lower than the variance shared with the other latent variables (squared correlation among them). Tables 1 and 2 show that this does not occur in any of the situations, which corroborates the discriminant validity of the dimensions that were found.

\section{Identification of the scale dimensions}

The labeling process of the dimensions sought to determine names that globally, and if possible neutrally, represent the characteristics grouped into each dimension. The traits with higher loading and the facets (groups within the dimension) that represent the dimensions with some precision were evaluated. The first dimension was defined as CREDIBILITY and contains facets such as Responsible, Secure, Reliable, Confident, Correct, Respectable, Loyal and Consistent. According to this study, a brand that typifies these dimensions is Volkswagen, which, for a long time, advertised using the slogan "you know it, you trust it".

The second dimension was named JOY. It includes facets such as Cool, Happy, Festive, Extrovert, Fun, Good-natured, Playful. The Havaianas brand is a good example of this dimension of brand personality. The brand became famous through management which, among other things, implemented colors into the flip flops and adopted a cheerful advertising campaign.

The third dimension was labeled AUDACITY, a mixture of characteristics such as Modern, Daring, Creative and Up-to-date. An example of the Audacity dimension is Nike, with its modern, innovative style, which is reflected in its advertising and the constant innovation of its products.

The fourth dimension was labeled SOPHISTICATION, including facets such as Chic, Upper Class, Elegant, Sophisticated and Glamorous. The Nokia and Motorola brands of cell phones are good examples of this dimension. These brands rely heavily on their design and style, with high price levels as a source of image and personality construction. 
The fifth dimension is SENSITIVITY and includes facets such as Delicate, Sensitive, Romantic and Enchanting. The Natura brand is a clear example of this dimension of brand personality, according to the data of this study. Natura is concerned with human beings and the environment in general and is dedicated (in its products and publicity) to forging a bond with consumers, seeking to understand them and accompany them as they grow.

Therefore, Figure 2, below, shows details of these dimensions and the final traits of the resulting scale in the Brazilian context.

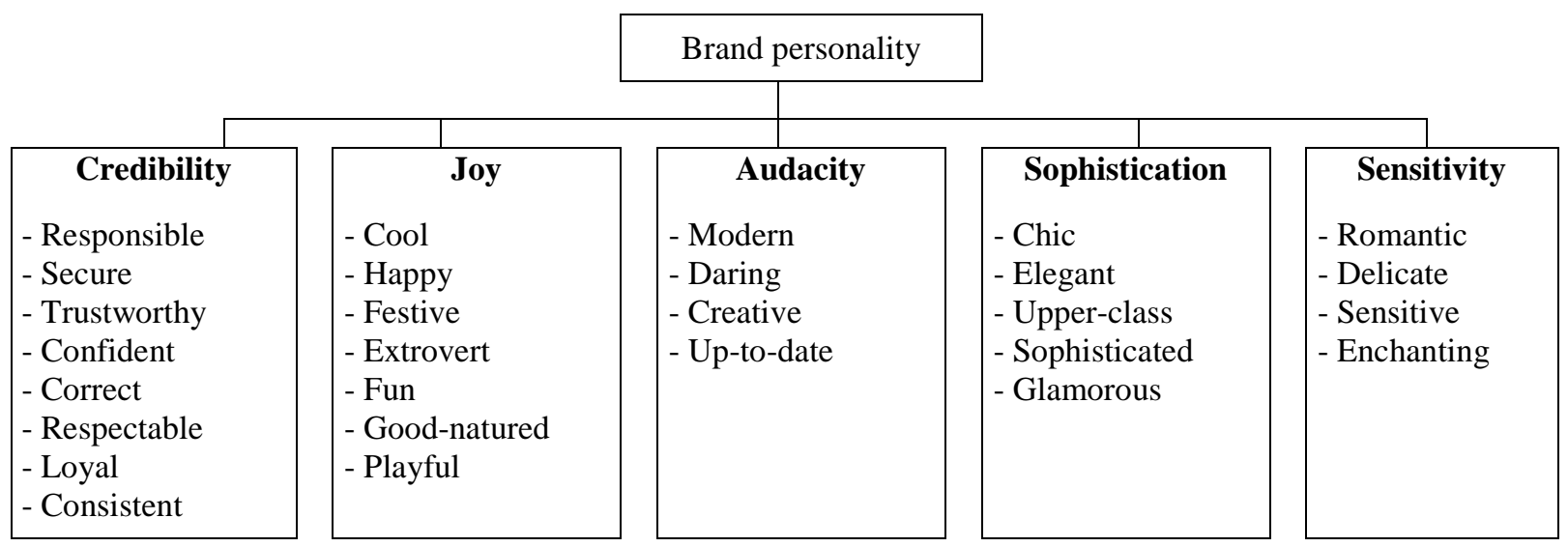

Figure 2. The Final Brand Personality Scale in Brazil.

Source: Research data.

\section{Discussion of Results}

In general, there are similarities and differences between the dimensions found in Brazil and the factors found in other contexts (J. Aaker, 1997; J. Aaker et al., 2001). Table 3 shows a comparison between the dimensions found in the USA, Spain and Japan and the results of the Brazilian context, providing examples of each dimension with some of its characteristic traits in that country.

Table 3

Comparison between the Brand Personality Dimensions in Brazil and in Other Contexts

\begin{tabular}{|c|c|c|c|}
\hline Brazil & USA & Japan & Spain \\
\hline CREDIBILITY & COMPETENCE & COMPETENCE & PASSION \\
\hline $\begin{array}{l}\text { Traits (e.g.): loyal, } \\
\text { consistent, correct, } \\
\text { confident, respectable, } \\
\text { etc. }\end{array}$ & $\begin{array}{l}\text { Traits (e.g.): trustworthy, } \\
\text { intelligent, technical, } \\
\text { successful, leader, } \\
\text { confident, hard-working. }\end{array}$ & $\begin{array}{l}\text { Traits (e.g.): consistent, } \\
\text { responsible, confident, } \\
\text { masculine, patient. }\end{array}$ & $\begin{array}{l}\text { Traits (e.g.): fervent, } \\
\text { intense, spiritual, } \\
\text { mystical, bohemian. }\end{array}$ \\
\hline JOY & SINCERITY & SINCERITY & SINCERITY \\
\hline $\begin{array}{l}\text { Traits (e.g.): happy, } \\
\text { extrovert, festive, funny, } \\
\text { etc. }\end{array}$ & $\begin{array}{l}\text { Traits (e.g.): realistic, } \\
\text { familiar, honest, cheerful, } \\
\text { friendly, sincere. }\end{array}$ & $\begin{array}{l}\text { Traits (e.g.): kind, warm, } \\
\text { attentive. }\end{array}$ & $\begin{array}{l}\text { Traits (e.g.): correct, } \\
\text { attentive, sincere, } \\
\text { realistic. }\end{array}$ \\
\hline AUDACITY & EXCITEMENT & EXCITEMENT & EXCITEMENT \\
\hline $\begin{array}{l}\text { Traits (e.g.): daring, up- } \\
\text { to-date, modern, creative. }\end{array}$ & $\begin{array}{l}\text { Traits (e.g.): daring, } \\
\text { modern, exciting, young, } \\
\text { spirited, imaginative. }\end{array}$ & $\begin{array}{l}\text { Traits (e.g.): fun, talkative, } \\
\text { optimistic, friendly, } \\
\text { spirited, contemporary. }\end{array}$ & $\begin{array}{l}\text { Traits (e.g.): cheerful, } \\
\text { extrovert, daring, young, } \\
\text { imaginative. }\end{array}$ \\
\hline
\end{tabular}


Table 3 (continued)

\begin{tabular}{|c|c|c|c|}
\hline Brazil & USA & Japan & Spain \\
\hline SOPHISTICATION & SOPHISTICATION & SOPHISTICATION & SOPHISTICATION \\
\hline $\begin{array}{l}\text { Traits (e.g.): chic, upper- } \\
\text { class, elegant, } \\
\text { sophisticated, etc. }\end{array}$ & $\begin{array}{l}\text { Traits (e.g.): upper-class, } \\
\text { glamorous, attractive, } \\
\text { feminine. }\end{array}$ & $\begin{array}{l}\text { Traits (e.g.): elegant, } \\
\text { romantic, chic, } \\
\text { sophisticated, extravagant. }\end{array}$ & $\begin{array}{l}\text { Traits (e.g.): glamorous, } \\
\text { chic, elegant, confident, } \\
\text { leader }\end{array}$ \\
\hline SENSITIVITY & RUGGEDNESS & PEACEFULNESS & PEACEFULNESS \\
\hline $\begin{array}{l}\text { Traits (e.g.): delicate, } \\
\text { sensitive, romantic. }\end{array}$ & $\begin{array}{l}\text { Traits (e.g.): adventurous, } \\
\text { masculine, firm, rugged. }\end{array}$ & $\begin{array}{l}\text { Traits (e.g.): shy, sweet, } \\
\text { naïve, dependent, childish. }\end{array}$ & $\begin{array}{l}\text { Traits (e.g.): affectionate, } \\
\text { sweet, kind, naïve, } \\
\text { peaceful. }\end{array}$ \\
\hline
\end{tabular}

Note. Source: Aaker, J. (1997). Dimensions of brand personality (p. 352). Journal of Marketing Research, 34(3), 347-356. doi: 10.2307/3151897, Aaker, J., Benet-Martinez, V., \& Garolera, J. (2001). Consumption symbols as carries of culture: a study of Japanese and Spanish brand personality constructs (p. 500 and 505). Journal of Personality and Social Psychology, 81(3), 492-508. doi: 10.1037/0022-3514.81.3.492, and research data.

Evaluating the traits found in foreign dimensions and the characteristics of Brazilian dimensions, some overlapping of how the brand is perceived can be seen, i.e., some dimensions of brand personality are identical or very similar to those of different contexts. The SOPHISTICATION dimension was found to be almost fully identical in all four contexts, with some small changes in the traits of which it is made up. In all four countries, consumers perceive some brands as highly sophisticated. Moreover, the brands with high scores in this dimension in Brazil are almost all global brands such as Nokia, Motorola, Nike, Reebok, Nestlé and Avon.

Two Brazilian dimensions were close to the dimensions found in other countries. The CREDIBILITY dimension found in Brazil bears some similarity to the Competence dimension found in the United States and Japan in addition to a mixture of some traits in the Sincerity dimension found in the other three contexts. The AUDACITY dimension bears some resemblance to the Excitement dimensions, sharing common traits (modern, daring, young). However, the Brazilian context also has two dimensions with unique configurations in terms of their traits. These bear little resemblance to the factors identified in the other countries.

The JOY dimension unites cultural characteristics and values associated with Brazil and the Brazilian people. Brazil is perceived as a festive, friendly and spirited country. Hitching a ride on this facet, the Havaianas brand has adopted a position that its strategy is to globalize the brand. Studies involving Americans have shown that Brazil is synonymous with fun and that a friendly style is a Brazilian trait (Rezende-Parker, Morrison, \& Ismail, 2003). Another unique factor found in the Brazilian context is the SENSITIVITY dimension which, despite having similar traits to SINCERITY and PEACEFULNESS dimensions that were found in other contexts, is the complete opposite of the Ruggedness found in the USA. While this American dimension reflects typically American values (this dimension was not found in any other country), such as strength, masculinity and the ideal of freedom, the SENSITIVITY dimension reflects a certain mildness, femininity and emotion, traits found in the image of Brazilian brands. Texts on the formation of Brazilian society emphasize that in the Brazilian lifestyle what is predominant is "the lack of any form of co-existence that is not dictated by ethics and an emotional background" (Holanda, 1987, p. 107).

Some authors have noted that cultural aspects, within the context of globalization, lead to two extremes and increased complexity: aspects of the local culture may be preserved and even strengthened, while countries and regions are at the same time becoming more similar in terms of their needs and shared beliefs (Hermans \& Kempen, 1998). Arnett (2002) states that most people develop a bi-cultural identity that combines their local identity with an identity that is related to global culture. Therefore, the dimensions of brand personalities were expected to reflect shared local beliefs, values and behavior with traits of global culture (J. Aaker et al., 2001; Sung \& Tinkham, 2005). 


\section{Personality of the brands used in the study}

Table 4 positions the brands used in the study within the dimensions extracted after the confirmatory factor analysis outlined above. As reported, the respondents evaluated how far each characteristic described a given brand, on a scale of one to ten $(1=$ in no way describes the brand; $10=$ totally describes the brand). The general means were computed for each dimension and these were listed with the mean that each of the 24 brands obtained in each dimension. In this case, the highest scoring brands had results greater than 1.00 .

Table 4

Position of Brands Used in the Study in Each Brand Personality Dimension

\begin{tabular}{|c|c|c|c|c|c|c|}
\hline \multirow[t]{2}{*}{ Dimensions } & \multicolumn{6}{|c|}{ Brands } \\
\hline & Avon & Natura & Bombril & Assolan & OMO & Ariel \\
\hline & $\mathrm{n}=86$ & $\mathrm{n}=111$ & $\mathrm{n}=107$ & $\mathrm{n}=86$ & $\mathrm{n}=98$ & $\mathrm{n}=78$ \\
\hline Credibility & 1.05 & 1.12 & 1.05 & 0.84 & 1.12 & 0.91 \\
\hline Joy & 0.83 & 0.94 & 1.12 & 1.11 & 0.82 & 0.79 \\
\hline Audacity & 0.94 & 1.14 & 0.86 & 0.98 & 0.92 & 0.90 \\
\hline Sophistication & 1.12 & 1.35 & 0.69 & 0.61 & 1.02 & 0.81 \\
\hline \multirow[t]{3}{*}{ Sensitivity } & 1.53 & 1.67 & 0.90 & 0.76 & 0.97 & 0.92 \\
\hline & Sadia & Perdigão & Brahma & Nova Schin & Coca-cola & Pepsi-cola \\
\hline & $\mathrm{n}=99$ & $\mathrm{n}=99$ & $\mathrm{n}=105$ & $\mathrm{n}=100$ & $\mathrm{n}=91$ & $\mathrm{n}=103$ \\
\hline Credibility & 1.12 & 1.05 & 0.82 & 0.70 & 0.94 & 0.89 \\
\hline Joy & 1.16 & 0.89 & 1.14 & 1.21 & 1.26 & 1.16 \\
\hline Audacity & 1.01 & 0.86 & 0.88 & 1.01 & 1.12 & 1.02 \\
\hline Sophistication & 1.12 & 0.92 & 0.75 & 0.58 & 1.03 & 0.84 \\
\hline \multirow[t]{3}{*}{ Sensitivity } & 1.22 & 0.99 & 0.78 & 0.64 & 0.98 & 0.86 \\
\hline & Kibon & Nestlé & Nike & Reebok & Havaianas & Rider \\
\hline & $\mathrm{n}=89$ & $\mathrm{n}=106$ & $\mathrm{n}=108$ & $\mathrm{n}=90$ & $\mathrm{n}=110$ & $\mathrm{n}=97$ \\
\hline Credibility & 1.05 & 1.10 & 1.04 & 1.01 & 0.97 & 0.93 \\
\hline Joy & 1.20 & 1.10 & 1.05 & 0.94 & 1.30 & 1.13 \\
\hline Audacity & 1.02 & 0.98 & 1.23 & 1.07 & 1.10 & 1.01 \\
\hline Sophistication & 1.03 & 1.13 & 1.31 & 1.17 & 0.93 & 0.84 \\
\hline \multirow[t]{3}{*}{ Sensitivity } & 1.37 & 1.31 & 0.91 & 0.86 & 1.14 & 0.85 \\
\hline & Banco Brasil & Bradesco & Volkswagen & Fiat & Nokia & Motorola \\
\hline & $\mathrm{n}=103$ & $\mathrm{n}=101$ & $\mathrm{n}=109$ & $\mathrm{n}=86$ & $\mathrm{n}=103$ & $\mathrm{n}=90$ \\
\hline Credibility & 1.15 & 0.98 & 1.11 & 0.97 & 1.08 & 1.00 \\
\hline Joy & 0.64 & 0.64 & 0.81 & 0.87 & 0.96 & 0.94 \\
\hline Audacity & 0.88 & 0.89 & 0.91 & 0.98 & 1.17 & 1.14 \\
\hline Sophistication & 1.05 & 0.93 & 1.02 & 1.02 & 1.37 & 1.36 \\
\hline Sensitivity & 0.74 & 0.75 & 0.87 & 0.93 & 1.10 & 0.96 \\
\hline
\end{tabular}

Note. Source: Research data. 
It can be seen that some brands have strength, and were highlighted, in only one dimension (such as the Banco do Brasil brand in the credibility dimension or the Brahma brand in the joy dimension), while other brands stood out in more than one dimension (Sadia had high evaluations in credibility, joy, sophistication and sensitivity, as did Nestlé). Other brands, however, had low scores in all dimensions (Bradesco, for example).

This procedure, along with hypothesis testing techniques (t-test or ANOVA) makes it possible to compare competitors, seeking to identify the differences between brand personalities. For example, in the steel wool category, Bombril is a brand with higher scores in the credibility dimension $(\mathrm{t}=$ 5.766; $\mathrm{p}<0.001)$ and in the sensitivity dimension $(\mathrm{t}=2.255 ; \mathrm{p}=0.025)$, whereas Assolan had higher scores in the audacity dimension $(\mathrm{t}=-2.573 ; \mathrm{p}=0.011)$.

\section{Conclusions}

The aim of this study was to evaluate brand personality dimensions in the Brazilian context, establishing a useful and practical scale for this purpose. The researchers and professionals who were interviewed confirmed the importance of this intangible attribute or dimensions of brands (Keller, 1993) for differentiation within a competitive environment. There was a clear perception of the utility of the scale as an instrument for a quantitative approach for measuring this construct, helping researchers and marketing professionals in the management and auditing of brands along with current and potential clients.

This study, in its confirmatory approach, made it possible to achieve a better understanding concerning the perception that consumers have of brands that are available on the Brazilian market, enabling the identification of the dimensions of brand personality that were labeled Credibility, Joy, Audacity, Sophistication and Sensitivity. These dimensions reflect some cultural values that are found in the Brazilian context and carried and transferred to brands through their products, publicity and general behavior (Kapferer, 2003). The results of this research made it possible to analyze the Brazilian dimensions in comparison with those found in other contexts, underlining the proposition that consumer symbols such as brands can carry common meanings between cultures and reconfirm culturally significant meanings of a given culture (J. Aaker et al., 2001; Arnett, 2002). The results help construct knowledge concerning the subjacent symbolic structures in different cultures (cross-cultural marketing), where they are mixed. There are also multiple facets with local and global influences shared by individuals at the same time (Hermans \& Kempen, 1998). Solomon (2008) debates the dynamics of transferred meanings of products and brands to other countries, be it the development of a single approach in several markets and cultures (etic perspective), or the distinct set of characteristics of behavior and personality in each country (emic perspective). The findings of this study are in accordance with those of J. Aaker et al. (2001) and Sung and Tinkham (2005), as some of the brand personality dimensions in Brazil portray a specific culture related to traits, emotions and values that are identified in the country's citizens.

As well as exploring a procedure that evaluates brand personality (Keller et al., 2008), this study made it possible to compare brands from different categories of products and services. The results show the strongest personality dimensions for each category of product or service and the differences among competitors, revealing in some cases quite different personalities. Considering the differences seen within a given category that shows no physical differences or differences in performance (e.g. steel wool), it can be concluded that when the functional and tangible attributes are similar, intangible attributes such as personality could help establish a form of differentiation and construct a competitive advantage for the brand in question.

For researchers, this study can serve as a tool for research that seeks to go deeper into the structure and the effects of brand personality since it offers a supporting scale in this specific context. For marketing professionals, this quantitative approach could be very useful for positioning and 
projecting the evolution of their brand, taking into account the opinion of consumers about brands that compete with each other in a determined segment.

\section{Limitations and Future Studies}

Nevertheless, it is important to point out some limitations of the study. The data collection procedure sought to balance limits of time and budget by using the internet as a means of finding and characterizing a sample by convenience. Thus, and considering that the profile of the final sample is similar to that of the internet-using population in Brazil at that time, caution should be exercised when generalizing the data in terms of the Brazilian population on the whole. The use of financial incentives, such as a prize draw for shopping vouchers, has the advantage of attracting and retaining the attention of the respondents, but may arouse suspicions in that it could lead to biased answers, thus making it one of the limitations of the study (Goritz, 2006).

During the exploratory phases, the procedures cited in the literature were taken into consideration (Churchill, 1979), along with the traits of the literature on personality studies and studies that had already been conducted on the theme in other contexts.

The critique by Azoulay and Kapferer (2003) concerning the operational concept of the brand personality variable may refer to a limitation, bearing in mind other more restricted conceptual focuses in the derivation of the concepts of human psychology. Furthermore, any comparisons between the Brazilian dimensions and those of other contexts should be made carefully since the studies were conducted at different times (the American study was published in 1997, the studies conducted in Japan and Spain were published in 2001, while the present study was conducted in 2005). As culture is a set of values, customs and beliefs that have a certain dynamic due to the evolution of the sociocultural scenario (Schiffman \& Kanuk, 2000), any alterations and development of values that stand out in given society influence the personality dimensions perceived in brands (J. Aaker, 1997). There is no evidence of abrupt changes in cultural values at this time, but this limitation deserves to be mentioned.

The scale developed in this study enables studies on brand personality to be extended into other branches and contexts, advancing beyond the internet using public in Brazil. The scale will allow the undertaking of longitudinal studies to evaluate the development and construction of brand personality involving a certain target public. Future research can also contribute to furthering the relationship between this facet of the brand and its effects on consumer behavior, exploring the effects of the brand personality construct on consumer responses in terms of behavioral loyalty, affective connection and engagement (Keller et al., 2008).

Received 8 July 2010; received in revised form 22 August 2011.

\section{Acknowledgments}

The authors would like to thank the editor, Jorge Carneiro, and the anonymous reviewers for their valuable contributions to the article. We would also like to express our appreciation to Professor Dr. Paulo Henrique Muller Prado (PPGADM-UFPR) for his important contribution to the data analysis and discussion of the findings during the latter stages of our research.

\section{References}

Aaker, D. (1996). Criando e administrando marcas de sucesso. São Paulo: Futura. 
Aaker, D. (1998). Brand equity, gerenciando o valor da marca. São Paulo: Negócio.

Aaker, D., \& Biel, A. (1993). Brand Equity and advertising: an overview. In D. Aaker \& A. Biel (Eds.), Brand equity and advertising (pp. 1-8). New Jersey: Lawrence Erlbaum Associates.

Aaker, J. (1997). Dimensions of brand personality. Journal of Marketing Research, 34(3), 347-356. doi: $10.2307 / 3151897$

Aaker, J., Benet-Martinez, V., \& Garolera, J. (2001). Consumption symbols as carries of culture: a study of Japanese and Spanish brand personality constructs. Journal of Personality and Social Psychology, 81(3), 492-508. doi: 10.1037/0022-3514.81.3.492

Aaker, J., \& Fournier, S. (1995). A brand as a character, a partner and a person: three perspectives on the question of brand personality. Advances in Consumer Research, 22(1), 391-395.

Allport, G. W. (1973). Personalidade: padrões e desenvolvimento. São Paulo: EPU.

Arnett, J. J. (2002). The psychology of globalization. American Psychologist, 57(10), 774-783. doi: 10.1037/0003-066X.57.10.774

Azoulay, A., \& Kapferer, J. N. (2003). Do brand personality scales really measure brand personality? Journal of Brand Management, 11(2), 143-155. doi: 10.1057/palgrave.bm.2540162

Batra, R., Lehman, R., \& Singh, D. (1993). The brand personality component of brand goodwill: some antecedents and consequences. In D. Aaker \& A. Biel (Eds.), Brand equity and advertising (pp. 83-96). New Jersey: Lawrence Erlbaum Associates.

Berry, N. C. (1988). Revitalizing brands. The Journal of Consumer Marketing, 5(3), 15-20. doi: $10.1108 / \mathrm{eb} 008228$

Biel, A. (1993). Converting image into equity. In D. Aaker \& A. Biel (Eds.), Brand equity and advertising (pp. 67-82). New Jersey: Lawrence Erlbaum Associates.

Brakus, J. J., Schmitt, B. H., \& Zarantonello, L. (2009). Brand experience: what is it? How is it measured? Does it affect loyalty? Journal of Marketing, 73(3), 52-68. doi: 10.1509/jmkg.73.3.52

Caprara, G. V., Barbaranelli, C., \& Guido, G. (1998). Personality as metaphor: extension of the psycholexical hypothesis and the five factor model to brand and product personality description. European Advances in Consumer Research, 3, 61-69.

Caprara, G. V., Barbaranelli, C., \& Guido, G. (2001). Brand personality: how to make the metaphor fit? Journal of economic Psychology, 22(3), 377-395. doi: 10.1016/S0167-4870(01)00039-3

Chernatony, L. de, \& Riley, F. D. O. (1998). Defining a brand: beyond the literature with experts interpretation. Journal of Marketing Management, 14(5), 417-443. doi: $10.1362 / 026725798784867798$

Churchill, G. A., Jr. (1979). A paradigm for developing better measures of marketing constructs. Journal of Marketing Research, 16(1), 64-73. doi: 10.2307/3150876

Cobanoglu, C., \& Cobanoglu, N. (2003). The effect of incentives in web surveys: application and ethical considerations. International Journal of Market Research, 45(4), 475-488.

Cunha, A. L., Luce, F. B., \& Klering, L. R. (1997, September). O valor de marca para o consumidor final a partir do conceito de brand equity em bens de conveniência. Proceedings of the Encontro Nacional da Associação Nacional de Pós-Graduação e Pesquisa em Administração, Angra dos Reis, RJ, Brazil, 21. 
De Toni, D., \& Schuler, M. (2003, September). Imagem de produto e comportamento do consumidor: explorando o processo de formação das imagens. Proceedings of the Encontro Nacional da Associação Nacional de Pós-Graduação e Pesquisa em Administração, Atibaia, SP, Brazil, 27.

Deutskens, E., Ruyter, K., Wetzels, M., \& Oosterveld, P. (2004). Response rate and response quality of internet-based surveys: an experimental study. Marketing Letters, 15(1), 21-36. doi: 10.1023/B:MARK.0000021968.86465.00

Durgee, J. F. (1988). Understanding brand personality. The Journal of Consumer Marketing, 5(3), 2125.

Ferrandi, J. M., Merunka, D., Valette-Florence, P., \& De Barnier, V. (2002). Brand personality: how well does a human personality scale apply to brands? Asia Pacific Advances in Consumer Research, 5, 53-60.

Fornell, C., \& Larcker, D. F. (1981). Evaluating structural equation models with unobservable variables and measurement error. Journal of Marketing Research, 18(1), 39-50. doi: $10.2307 / 3151312$

Fournier, S. (1998). Consumers and their brands: developing relationship theory in consumer research. Journal of Consumer Research, 24(4), 343-373. doi: 10.1086/209515

Frippiat, D., \& Marquis, N. (2010). Web surveys in the social sciences: an overview. Population-E, 65(2), 285-312. doi: 10.4074/S1634294110002030

Gardner, B. B., \& Levy, S. J. (1955). The product and the brand. Harvard Business Review, 33(2), 3339. doi: 10.1016/0737-6782(88)90037-9

Goldberg, L. R. (1990). An alternative "description of personality": the big-five factor structure. Journal of Personality and Social Psychology, 59(6), 1216-1229. doi: 10.1037/00223514.59.6.1216

Goritz, A. (2006). Incentives in web studies: methodological issues and a review. International Journal of Internet Science, 1(1), 58-70.

Grohmann, B. (2009). Gender dimensions of brand personality. Journal of Marketing Research, 46(1), 105-119. doi: 10.1509/jmkr.46.1.105

Gummesson, E. (2005). Qualitative research in marketing: road-map for a wilderness of complexity and undpredictability. European Journal of Marketing, 39(3-4), 309-327. doi: $10.1108 / 03090560510581791$

Hair, J. F., Jr., Anderson, R. E., Tatham, R. L., \& Black, W. C. (2005). Análise multivariada de dados. Porto Alegre: Bookman.

Hermans, J. M., \& Kempen, H. J. G. (1998). Moving cultures: the perilous problems of cultural dichotomies in a globalizing society. American Psychologist, 53(10), 1111-1120. doi: 10.1037/0003-066X.53.10.1111

Holanda, S. B. (1987). Raízes do Brasil. Rio de Janeiro: José Olympio Editora.

Kapferer, J. (2003). As marcas, capital da empresa. Porto Alegre: Bookman.

Keller, K. L. (1993). Conceptualizing, measuring and managing customer-based brand equity. Journal of Marketing, 57(1), 1-22. doi: 10.2307/1252054

Keller, K. L. (2003). Brand synthetis: the multidimensionality of brand knowledge. Journal of Consumer Research, 29(4), 595-600. doi: 10.1086/346254 
Keller, K. L., Aperia, T., \& Georgson, M. (2008). Strategic brand management: a European perspective. Harlow: Pearson Education Limited.

Levy, S. J. (1959). Symbols for sales. Harvard Business Review, 37(4), 117-124. doi: 10.1111/j.14679507.2009.00549.x

Malhotra, N. (2001). Pesquisa de marketing: uma orientação aplicada. Porto Alegre: Bookman.

Maroco, J. (2010). Análise de equações estruturais: fundamentos teóricos, software e aplicações. Perô Pinheiro: Report Number Ltda.

Martineau, P. (1958). The personality of the retail store. Harvard Business Review, 36(1), 47-55.

Merkens, H. (2004). Selection procedures, sampling, case construction. In U. Flick, E. Kardoff, \& I. Steinke (Eds.), A companion to qualitative research (pp. 165-171). London: Sage Publications.

Nuttin, J. (1969). A estrutura da personalidade. São Paulo: Livraria Duas Cidades.

Plummer, J. (1985). How personality makes a difference. Journal of Advertising Research, 24(6), 2731.

Pontes, N. G., \& Parente, J. G. (2008, September). Personalidade de marca: como se mede? Proceedings of the Encontro Nacional da Associação Nacional de Pós-Graduação e Pesquisa em Administração, Rio de Janeiro, RJ, Brazil, 32.

Rezende-Parker, A., Morrison, A. M., \& Ismail, J. A. (2003). Dazed and confused? An exploratory study of the image of Brazil as a travel destination. Journal of Vacation Marketing, 9(3), 243259. doi: $10.1177 / 135676670300900304$

Schiffman, L. G., \& Kanuk L. L. (2000). Comportamento do consumidor. Rio de Janeiro: LTC.

Shank, M. D., \& Langmeyer, L. (1994). Does personality influence brand image? The Journal of Psychology, 128(2), 157-164. doi: 10.1080/00223980.1994.9712719

Solomon, M. R. (2008). O comportamento do consumidor: comprando, possuindo e sendo. Porto Alegre: Bookman.

Sung, Y., \& Tinkham, S. F. (2005). Brand personality structures in the United States and Korea: common and culture-specific factors. Journal of consumer psychology, 15(4), 334-350. doi: $10.1207 / \mathrm{s} 15327663 \mathrm{jcp} 1504 \_8$

Supphellen, M., \& Gronhaug, K. (2003). Building foreign brand personalities in Russia: the moderating effect of consumer ethnocentrism. International Journal of Advertising, 22(2), 203226.

Urdan, F. T., \& Urdan, A. T. (2001, September). O impacto da marca sobre as preferências do consumidor: um experimento com cervejas. Proceedings of the Encontro Nacional da Associação Nacional de Pós-Graduação e Pesquisa em Administração, Campinas, SP, Brazil, 25 .

Zaltman, G. (2003). Afinal, o que os clientes querem? Rio de Janeiro: Campus. 